\title{
209 STATUS AND RECOGNITION OF SPORTSWOMEN IN INDIAN SOCIETY
}

Vasanthi Kadhiravan Department of Physical Education, University of Mumbai Mumbai, Maharashtra, India

10.1136/bjsm.2010.078725.209

In the early 1900s when club life was introduced in India, sporting activities also found a serious place in female lives due to the facilities provided. Women pioneers had started blazing the trail. Rajkumari Amrit Kaur, Health Minister in India first set an example for North Indian women by taking to competitive tennis. The efforts of such sporting personalities have yielded fruits. The female sensation in badminton today is world no 2 Saina Newhal. Similar legendary sportswomen are Karnam Malleshwari, Anju Bobby George, PT Usha and Sania Mirza. Even if they are a step ahead, a number of factors ensure that sportswomen stay two steps behind. Though the Indian culture looks up to a woman as a mother of a race, the Indian society is firm with the belief that women are naturally inferior to men because of the faith that a woman's duty is bound only to birthing and taking care of her family. The level of physical education and sports for females has been hampered because of the endless limitations. Their road to glory is a fight against prejudice, inferiority and discrimination. Customs and traditions seep their way into discouraging woman achievers. We need sportswomen of yesteryear to handle the reigns and encourage the upcoming generations. Our society has to work towards a massive cultural reform where we have a healthy work ethic. Until that is done Indian women will be only chasing a mirage, not medals, in international sporting events. 